\title{
Bile cast nephropathy
}

\author{
Shakiba Hassanzadeh $^{\mathbb{D}}$, Hamid Nasri ${ }^{*}$ \\ Nickan Research Institute, Isfahan, Iran
}

\author{
Correspondence to: \\ Hamid Nasri, Email: \\ hamidnasri@yahoo.com, \\ hamidnasri@med.mui.ac.ir \\ Received: 22 Sep. 2021 \\ Accepted: 14 Oct. 2021 \\ ePublished: 31 Oct. 2021 \\ Keywords: Bile cast nephropathy, \\ Hyperbilirubinemia, Renal \\ dysfunction
}

Citation: Hassanzadeh S, Nasri H. Bile cast nephropathy. J Prev Epidemiol. 2022;7(1):e08. doi: $10.34172 /$ jpe.2022.08

\begin{abstract}
Key point
Bile cast nephropathy $(\mathrm{BCN})$ is characterized by renal dysfunction and hyperbilirubinemia which is caused by the dysfunction of the hepatobiliary system. The pathogenesis of BCN includes renal tubular obstruction by bile casts, direct toxicity of bile acid on the tubular epithelial cells of the kidney, and severe liver dysfunction. The diagnosis of $\mathrm{BCN}$ is difficult and the patients may not be easily diagnosed. The treatment of $\mathrm{BCN}$ includes decreasing the levels of bile acid and bilirubin, reversal of the cause of hepatic injury, and albumin dialysis.
\end{abstract}

\section{Introduction}

Bile cast nephropathy (BCN), previously known as cholemic nephrosis, is a term that is referred to a variety of kidney damages such as proximal tubular injury and the presence of casts (containing bile materials) in the distal tubules in patients that have a severe hepatic obstruction (1). It occurs in patients that have dysfunction of the hepatobiliary system that leads to the co-existence of renal dysfunction and significant hyperbilirubinemia (2).

Pathogenesis of bile cast nephropathy The acute renal dysfunction in BCN is usually caused by various etiologies. Some of the various conditions that play a crucial role in the pathogenesis of $\mathrm{BCN}$ include conditions that alter the hemodynamic status such as renal tubular obstruction by bile casts, direct toxicity of bile acid on the tubular epithelial cells of the kidney, and liver dysfunction (3).

In the proximal renal tubules, organic solute transporters are responsible for the kidney-hepatic circulation of bile salts. In normal conditions, most of the bile acid is transported back to the liver by reabsorption in the ileum through portal blood circulation. Additionally, small amounts of bile acid are also are recovered in the renal system. However, the bile acid pumps of the hepatic cells upregulate during cholestasis to excrete the excessive direct bilirubin into the bloodstream which causes hyperbilirubinemia $(1,2)$. As a result, the clearance of bilirubin by the kidneys increases, in some patients from about 5\% to $90 \%$, mostly in the proximal convoluted tubules (1).

Recent studies have shown that bilirubin has direct toxicity on the renal tubular cells by the exertion of oxidative stress on the tubular cells leading to membrane injuries of the tubular cells. This leads to the hypertrophy of the tubular cells (1). Consequently, there is acute damage to the tubules resulting in necrotic and sloughed epithelial cells of the kidney, which leads to yellow-green pigments in the lumen of the tubules and pigmented granular casts $(1,3)$.

\section{Diagnosis of bile case nephropathy}

The diagnosis of $\mathrm{BCN}$ is difficult and the patients may not be easily diagnosed (1). It is important to note that studies have reported individuals who have a bilirubin concentration of more than $20 \mathrm{mg} / \mathrm{dl}$ are more susceptible to developing renal failure (2). The presence of leucine crystals in the urinary sediment is a marker of severe liver impairment (4). In addition, bile casts in the renal tubules turn green in color following Hall's special stain for bile $(1,3)$.

\section{Treatment of bile cast nephropathy}

The formation of bile casts may lead to impairment of the proximal tubules that may be reversible with different outcomes (1). The treatment of BCN is mainly based on decreasing the levels of bile acid and bilirubin or reversing the causes of liver impairment. However, it has been reported 
that treatment of BCN may result in various outcomes. There is no specific treatment approach for BCN; however, there are some options. For example, removing the cause of obstruction, such as stones or tumors, with ERCP (endoscopic retrograde cholangiopancreatography) is a treatment option. In addition, plasmapheresis may be utilized in the removal of increased bilirubin; it is usually used in the management of liver dysfunction. In addition, albumin dialysis is another option to remove albuminbound substances such as bilirubin, bile acids, and liver toxins (1).

Authors' contribution

Primary draft by HN. Scientific edit by SH. Both authors read, signed and approved the final paper.

Conflicts of interest

The authors declare that they have no competing interests.

Ethical issues

Ethical issues (including plagiarism, data fabrication, double publication) have been completely observed by the authors.

\section{Funding/Support}

None.

\section{References}

1. El Chediak A, Janom K, Koubar SH. Bile cast nephropathy: when the kidneys turn yellow. Renal Repl Ther. 2020;6:15. doi: 10.1186/s41100-020-00265-0.

2. Patel J, Walayat S, Kalva N, Palmer-Hill S, Dhillon S. Bile cast nephropathy: A case report and review of the literature. World J Gastroenterol. 2016;22:6328-34. doi: 10.3748/wjg.v22. i27.6328.

3. Torrealba J, Sweed NT, Burguete D, Hendricks AR. Bile Cast Nephropathy: A Pathologic Finding with Manifold Causes Displayed in an Adult with Alcoholic Steatohepatitis and in a Child with Wilson's Disease. Case Rep Nephrol Dial. 2018;8:207-15. doi: 10.1159/000493231.

4. Jain K, Gupta A, Singh HK, Nickeleit V, Kshirsagar AV. Bile cast nephropathy. Kidney Int. 2015;87:484. doi: 10.1038/ ki.2014.233. 